\title{
NEO-DADA, DECONSTRUCCIÓN Y \\ PSICOANÁLISIS EN LA OBRA DE RAIMUND ABRAHAM
}

\author{
EUGENIO MANGIA GUERRERO
}

Fecha de recepción: 08/2016

Fecha de aceptación: 10/2016

\begin{abstract}
Resumen:
Este ensayo tiene el propósito de investigar como objetivo la obra de Raimund Abraham titulada "Hinge-Chair" 1970/71. La intención de estudiar dicha obra tiene un doble designio, el primero es rendir un homenaje personal y póstumo a quien fue en vida mi profesor de titulación. El segundo es el de auscultar los motivos conscientes e inconscientes de la obra desde diferentes ópticas como la deconstrucción filosófica y el psicoanálisis Jungiano. Con el presente ensayo se propone poner en valor una obra de arte perteneciente al neo-vanguardismo de la década de los 60 y 70 y establecer su deuda con la vanguardia histórica de principios de siglo XX.
\end{abstract}

Palabras clave: Neo-Dada, deconstrucción, psicoanálisis, arte contemporáneo, estética, readymade, ontología

\begin{abstract}
:
This essay looks into Raimund Abraham's work "Hinge-Chair" (1970/71). This purpose has two objectives, the first one is to make a personal and posthumous tribute to whom in life, was my dissertation professor. The second one is to uncover motives, both conscious and unconscious, of this work from different points of view, such as philosophical deconstruction and Jungian psychoanalysis. This work offers a look of a work of art about neo avant-garde from the 60's and 70 's and establishes its responsibility with historical avant-garde in the 20th century.
\end{abstract}

Key words: Neo-Dada, Deconstruction, psychoanalysis, contemporary art, aesthetics, Ready-made, ontology

\section{Autor:}

Máster Eugenio Mangia Guerrero, Pontificia Universidad Católica del Ecuador, Facultad de Arquitectura, Diseño y Artes, Quito, Ecuador. evmanga@puce.edu.ec. 


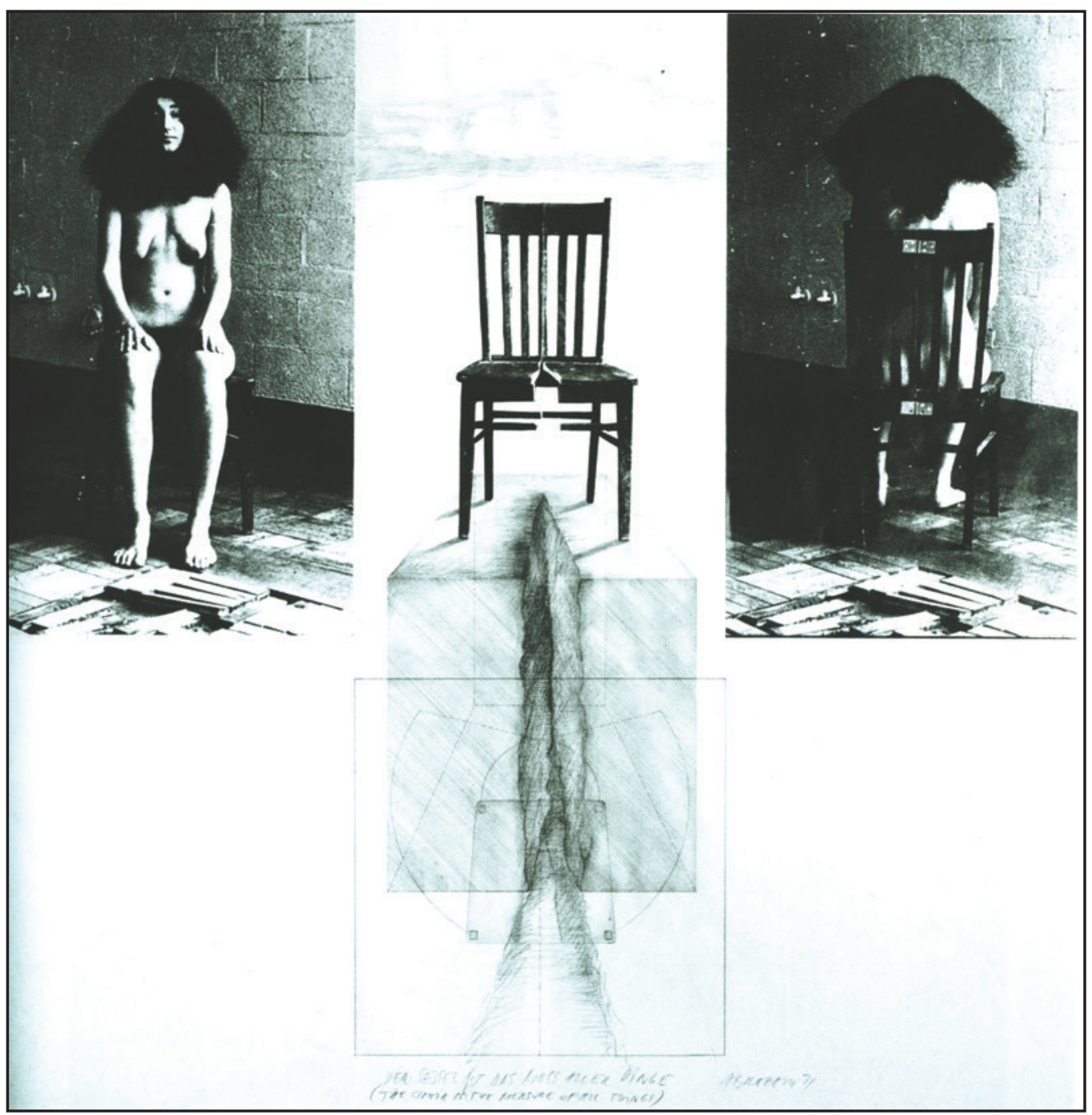

Hinge Chair, Raimund Abraham [UN] BUILT, 2010, p.45.

\section{Introducción}

Revelar qué ha realizado el artista supone principalmente conocer la obra $y$ también estudiar el desenvolvimiento de su actividad en los momentos y actitudes que le han caracterizado, examinar los escritos, las expresiones de ideas artísticas, las relaciones mantenidas con otros artistas y movimientos; en suma, reunir un cúmulo de elementos y seleccionarlos adecuadamente de suerte que puedan servir para investigaciones posteriores. Es estudiar por qué el artista ha realizado de tal manera o sea que ha ejecutado y proyectado de cierto modo, exige indagaciones en un conjunto a menudo bastante complejo de hechos intrínsecos, de estados de ánimo y elementos prácticos, de relaciones humanas y de necesidades pragmáticas, psicológicas, de posiciones intelectuales y factores técnicos; y tratar de comprender cómo todo esto haya obrado en el ánimo del artista, cuánta parte haya sido aceptada o rechazada, o cuál ha sido su interpretación. Búsqueda nada fácil, por cierto, la mayoría de las veces, de la cual tendría que resultar la personalidad estudiada, el ambiente de su actividad, y el mundo de ideas artísticas del que ha participado, dándole expresión y forma a un objeto o proceso de arte. 
Un objeto de arte, al contrario de cualquier objeto, posee una intención estética. Una intención estética en el arte no siempre depende del objeto o de las cualidades estéticas del objeto. Por ejemplo, en el caso de Marcel Duchamp en donde se apropia de un objeto cotidiano el "ready-made" y por medio de la operación de cambiar su contexto o descontextualizarle al objeto se podrá clasificarlo como un objeto de arte. Mientras todos los objetos, sean diseñados o no, tengan una estética inherente, el objeto en el caso de Duchamp recibe su apelación como arte no por la estética del objeto o las cualidades del objeto, sino más bien desde algo externo al objeto, en el caso de Duchamp y su "fuente" (urinario) un cambio de contexto. Por lo tanto, se podrá decir que una intención estética, sin incluir necesariamente la idea del objeto de las cualidades del objeto, le califica como algo artístico.

En el tema especial de los artistas, que son el enfoque de esta investigación, se trata de movimientos inspirados por Duchamp y posteriores a él. En este caso particular se toma en cuenta el Neo-Dada de Raimund Abraham, que tuvo ciertas afinidades con el Fluxus y otros movimientos afines, como los Actionists y Action-Art, todos estos movimientos conforman parte de la neo-vanguardia de los años sesentas, setentas y que hasta hoy día sigue sosteniendo una influencia sobre el arte contemporáneo.

Neo-Dada fue un movimiento que consistió de manifestaciones audio-visuales, literarias y que tenían similitudes en sus intenciones y método con obras artísticas del temprano Dada. Había también, una dimensión internacional al movimiento aparte de los EE.UU., había manifestaciones particularmente en Europa y Japón, además sirvió como un referente en la fundación de Fluxus, Arte Pop y Nouveau réalisme. Neo-Dada fue ejemplificado por su uso de materiales modernos, imágenes populares y contrastes absurdos. Fue una reacción al emocionalismo personal del Expresionismo Abstracto y tomó inspiración en las prácticas de Marcel Duchamp, Kurt Schwitters y Frederick Kiesler; todos ellos negaron conceptos estéticos tradicionales. En este sentido el proceso creativo fue privilegiado sobre el producto final (Craft, 2012). Con su llegada a los EE.UU., Abraham inicialmente trabajó por un tiempo muy breve con Frederick Kiesler: "Once upon a time there was a young Austrian architect called Raimund Abraham who travelled to New York, got to know some famous colleagues there, had his work promoted by Frederick Kiesler, and soon developed his vision of an entirely new and radical architecture of the future (Lepik, Marboe, p.118).” En una entrevista con Peter Marboe Abraham comenta sobre su relación con Keisler en Nueva York:

That was an unforgettable
experience. The last year of his
life (Kiesler), when I visited him,
I entered his studio and heard
a faint voice from somewhere,
so I followed the voice. He was
working on a sculpture of a horse
lying on its back with its legs
stretched into the air. He was
lying inside the belly of the horse
and writing a poem in gold letters
on the inner shell of the horse's
body. And I realized immediately
that there was such an incredible
spatial affinity between the belly
of the horse and his endless house
and his obsession to discover
a new space different from all
space he had ever known; a
total metamorphosis of a single
idea removed from its content
(Abraham, 2011, p. 233).

Internacionalmente, Raimund Abraham ha sido conocido mucho más como arquitecto por haberse desenvuelto reconocidamente en 
este campo disciplinario; no obstante, también es poseedor de un extraordinario cuerpo creativo de arte contemporáneo que fue desarrollado en gran parte durante los años sesentas, setentas, ochentas y noventas.

\section{Abraham's vision takes aim at the border line: the limits of the possible, technically as well as conceptually. There is our chance and therein lies the conclusion of its own verdict (Groihofer, Schmied, 2011, 1983, p. 226).}

La obra en cuestión es específicamente titulada "Hinge-Chair" 1970/71, una obra ejecutada por Abraham en la ciudad de Nueva York y que fue expuesta en una instalación posterior en el Museo Universitario, de la Ciudad de México en 1975, con la siguiente instrucción textual:

\section{Classify Objects by the number}

of their juxtapositional possibilities

Create architectural objects

through functional contradictions.

Make a Hinge-Chair.

Study the principal of the Hinge

as reconciliation of the cut.

Synchronize juxtapositions

In space and time.

When I move something,

I move.

La obra en sí es heredera del legado del ready-made duchampiano por tratarse de una silla cualquiera de madera, sobre la cual se le ha practicado un corte y como sugiere el enunciado de Abraham se le ha puesto dos bisagras en la parte posterior de la silla. Por lo pronto, esto es lo concerniente a la parte técnica de la obra, pero la parte conceptual que es la más interesante e importante es lo que será objeto de análisis. Lo que indica Abraham en su escrito es que se estudia el principio de la bisagra como una "reconciliación del corte." Además, la puesta en escena de la obra involucra una modelo, una joven mujer desnuda que se sienta sobre la silla y es fotografiada a modo de un registro secuencial recordando las fotografías del siglo XXI de Eadweard Muybridge. Una obra fotográfica muy conocida por Abraham y que a veces utilizaba en su propia obra.

Adicionalmente, existe un dibujo a la manera de un fotomontaje en perspectiva que ilustra la silla y un corte en el piso que replica de manera telúrica el corte practicado en la silla. Puesto sobre dicho corte hay un cuadrado que contiene una vista superior de la silla con sus respectivos movimientos giratorios de apertura y cierre. La fotografía de la silla se encuentra puesta entre la tierra y el cielo, ilustrado con una nube. Según M. Heidegger, "sobre la tierra” significa "bajo el cielo" ... "De una unidad original derivan cuatro principios: Tierra y Cielo, Mortal y Divino”, “... Los mortales son hombres... Sólo el hombre muere, pero mientras permanece en la tierra, bajo el cielo, participa de lo Divino" (Norberg-Schulz, Heidegger, 2001,1967, P.54).

He (Abraham) believes in the sacred, and he brings his offerings and respects to the Earth and to the Heavens. His silences resonate in deep respect of echoing man's inner breathing sounds, sounds that respond to the synapses of the soul... (Groihofer, Hejduk, 2011, p. 215).

La obra en esencia trata de lo ontológico, la supuesta posibilidad de un discurso sobre lo que 'es', el decible y decidido logos sobre la presencia y ausencia de la poética del ser humano, su poiesis. Observamos el objeto (silla) 

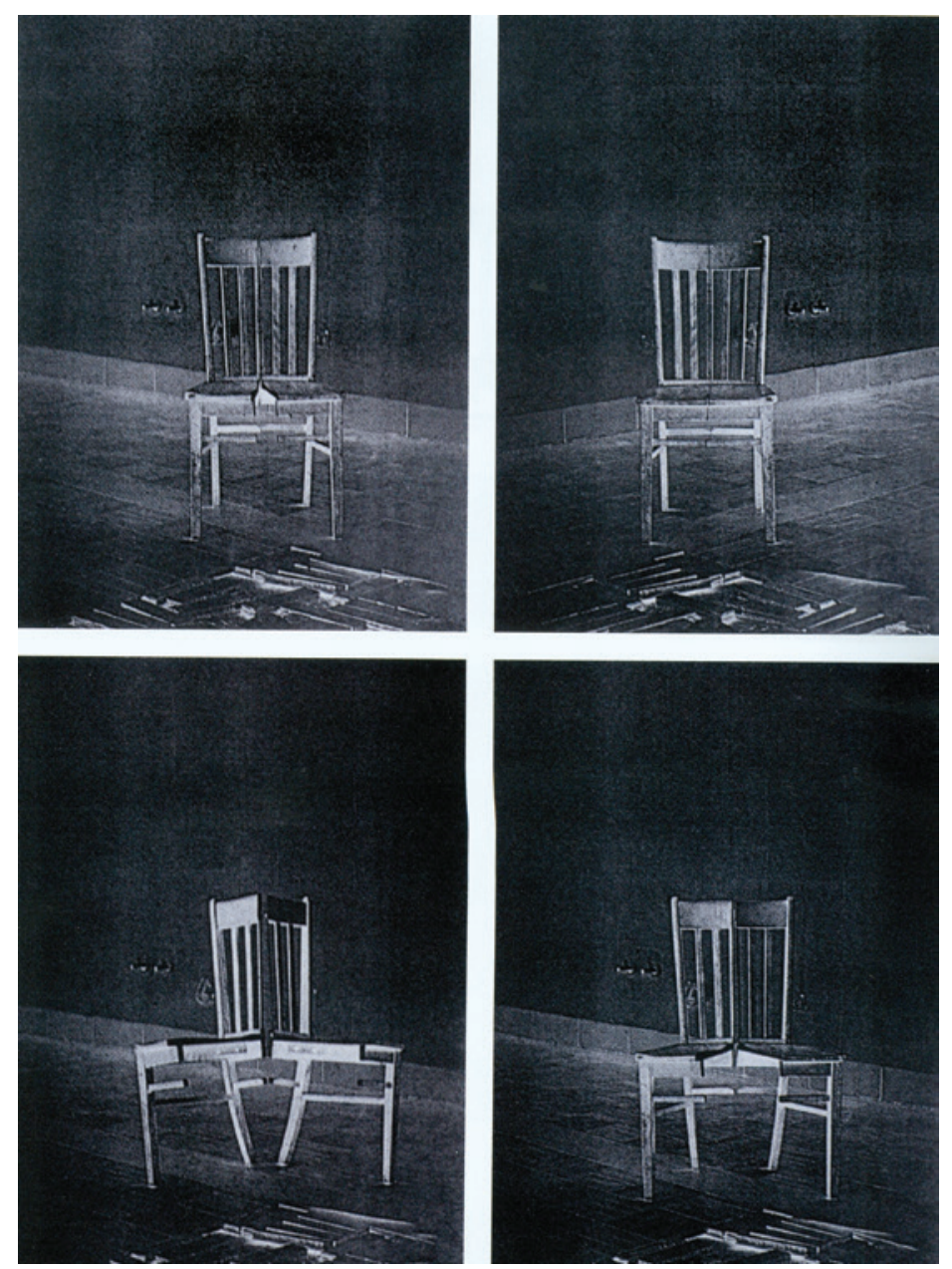

Hinge Chair, Raimund Abraham [UN] BUILT, 2010, p.46

ausente de la presencia humana. Se presume aseverar, acertar, rescatar, de reinventar eso que la tradición estética y filosófica ha intentado olvidar o suprimir: la invención de la verdad por medio de lo que los antiguos griegos llamaban poiesis, su intervención, es decir, el simulacro de su verosimilitud.

"Make a Hinge-Chair. Study the principal of the Hinge as reconciliation of the cut." Curiosamente, en español bisagra (hinge) es un sustantivo femenino. Las ventanas tienen un funcionamiento similar. Al igual que las puertas, suelen contar con bisagras que hacen posible su movimiento y, por lo tanto, su apertura y su cierre. En el lenguaje coloquial, la idea de bisagra se utiliza para calificar al acontecimiento o momento que marca un cambio de estado o de situación: "Los analistas consideran que mayo será un mes bisagra en la economía local debido al vencimiento de los bonos de la deuda", "La detención de la presidenta sería una bisagra en la historia nacional" (http://definicion.de/bisagra). Tal vez, con el lenguaje, y con el texto se pone en tela de juicio la metafísica de la presencia.

En el mismo "cuerpo", tanto físico como textual, de lo expresado se pretende una rigidez unívoca o una polisemia regulada. Un candado abierto a un doble sentido que ya no forma parte de un solo sistema. No obstante, lo que intenta Abraham es también reconciliar el corte (con la bisagra/mujer), pero esta reconciliación seria de un nuevo orden en donde la fractura, fisura practicada será (re)unida para funcionar de manera más dinámica que espera la 

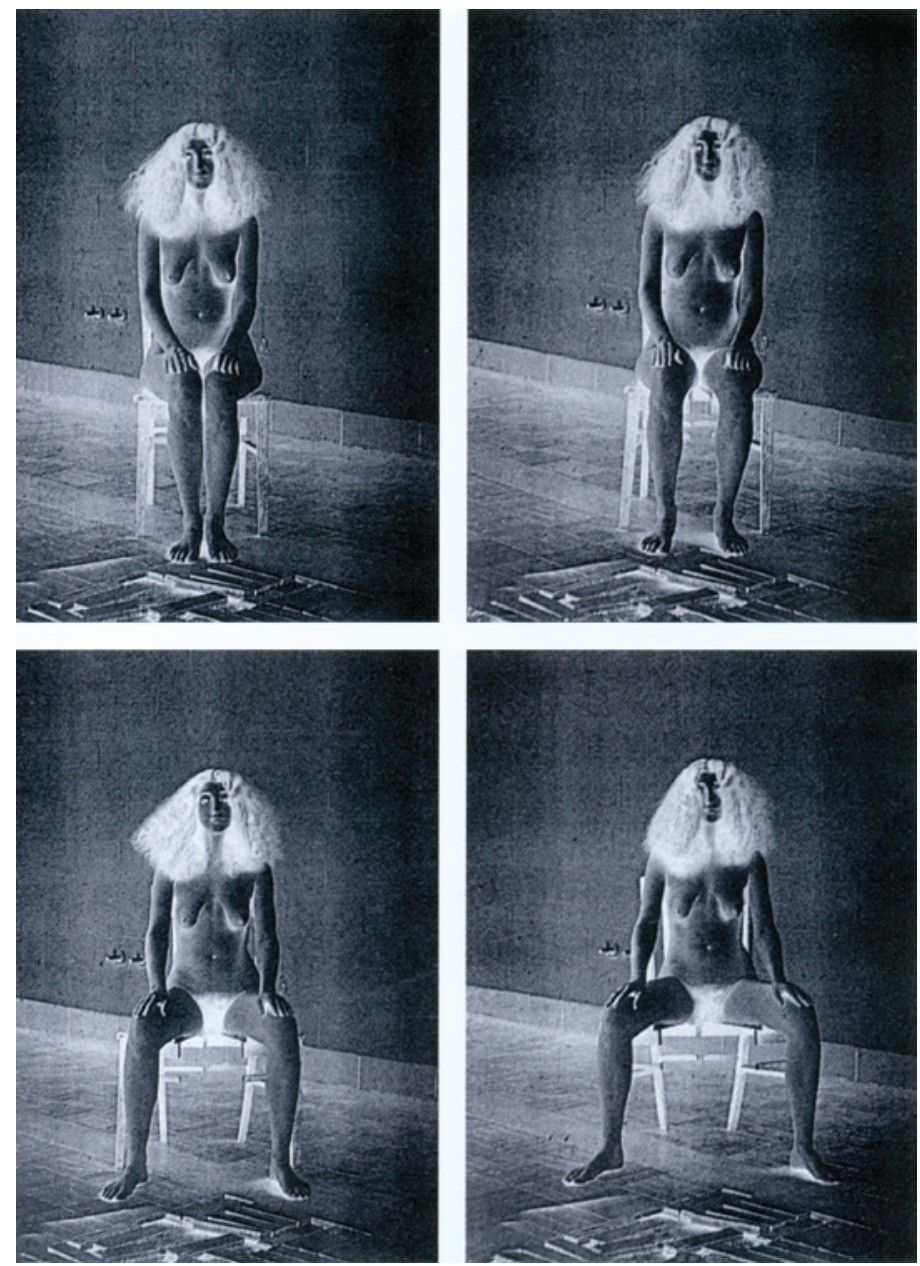

Hinge Chair, Raimund Abraham [UN] BUILT, 2010, p. 47

posibilidad de una penetración semejante para el psicoanálisis que según Jacques Derrida en $O f$ Grammatology comenta:

The hinge [brisure] marks the impossibility that a sign, the unity of the signifier and a signified, be produced within the plenitude of a present and an absolute presence. That is why there is no full speech, however much one might wish to restore it with or against psychoanalysis (Derrida, Kamuf, 1967, 1991, p. 41).

Es precisamente un asunto de restauración psicoanalítica y más específicamente del psicoanálisis jungiano que le concierne a esta investigación por existir un subtexto, por no decir, un subconsciente arquetípico como signo latente con respecto a esta obra de Abraham. El tema de lo femenino es preponderante en los símbolos utilizados en las diferentes fases de la obra en cuestión. Pero, ¿Qué es una bisagra [brisure]? Bisagras articulan, pero ¡cómo (des) articular esta obra tan articulada? Articulación, del vocablo latino articulatio, es el acto y el resultado de articular: la unión o la combinación de distintos elementos que otorga una cierta libertad a cada uno. Una articulación, en este marco, puede ser el vínculo que se establece entre dos piezas y que posibilita el movimiento de ambas (http://definicion.de/articulacion).

En otro escrito de Derrida, el “Tímpano”, capítulo introductorio de "Márgenes de la Filosofía", una referencia a la arquitectura desde la articulación podrá ser útil, aunque sea en sentido oblicuo. En arquitectura, se denomina tímpano, palabra proveniente del griego $\tau u ́ \mu \pi \alpha v o v$ y del latín tympanum, al espacio delimitado entre el 
dintel y las arquivoltas de la fachada de una iglesia o el arco de una puerta o ventana. También es el espacio cerrado delimitado dentro del frontón en los templos clásicos (https://es.wikipedia.org/ wiki/Tímpano). Escribe Derrida en "Tímpano": "No sólo de la pared abrigada del tímpano, sino del conducto vestibular' (1994, p. 24).”:

\begin{abstract}
${ }^{5}$ Termino de anatomía... Vestíbulo genital, la vulva y todas sus partes hasta la membrana himen exclusivamente. Se dice también del espacio triangular limitado por delante y lateralmente por las alas de las ninfas [labios menores de la vulva], $y$ por detrás por el orificio de la uretra; por este espacio se penetra al practicar el corte vestibular... Ovidio por el contrario con más razón, parece, lo extrae de Vesta porque el vestibulo contenía un fuego encendido en honor de Vesta, diosa de lo propio, de la familiaridad, del hogar doméstico (ibid., p. 24).
\end{abstract}

Pero antes de entrar en materia psicoanalítica, primero será necesario establecer ciertos conceptos Jungianos; quizás el más elemental es la subconsciencia como estado de funcionamiento caracterizado por falta de control sobre los instintos e identificación con los complejos. "Para el Logos, la inconsciencia es el pecado original, la maldad misma (Jung, 2011, p. 133).” El inconsciente es vasto e inagotable. No es simplemente lo desconocido o el repositorio de pensamientos y emociones conscientes que han sido reprimidos, sino que incluye contenidos que se pueden hacer o se harán conscientes. El inconsciente también contiene funciones "psicoides" 1 qué no son capaces de llegar a la consciencia y de las cuales sólo tenemos un conocimiento indirecto, como la relación entre materia y espíritu. En general, la actitud compensatoria del inconsciente opera para mantener el equilibrio psíquico.

1 Psicoide- Concepto aplicable a virtualmente cualquier arquetipo, que expresa la conexión entre psique y materia.
A nivel personal, son las motivaciones personales no reconocidas conscientemente que aparecen en los sueños, o los significados de situaciones cotidianas que hemos pasado por alto, o conclusiones que no hemos podido sacar, o afectos que nos hemos permitido, o criticas que hemos evitado (Jung, 2007, p. 148).

Jung atribuyó al inconsciente una función creativa, ya que presenta a la consciencia contenidos necesarios para la salud psicológica. Luego otro concepto ligado es el del inconsciente colectivo, lo cual es una capa estructural de la psique humana que contiene elementos heredados, pero que difiere del inconsciente personal. El inconsciente colectivo comprende toda herencia espiritual de la evolución de la humanidad, que nace nuevamente en la estructura cerebral de cada individuo (Jung, 2015a). Jung derivó su teoría del inconsciente colectivo de la ubicuidad de los fenómenos psicológicos que no podían explicarse con base en la experiencia personal. La importancia de la actividad de la fantasía inconsciente.

El inconsciente colectivo-
antes de entrar en detalles-
parece estar constituido por
motivos mitológicos o imágenes
primordiales, razón por la cual
mitos de todas las naciones son sus
verdaderas exponentes. De hecho,
toda mitología puede considerarse
una especie de proyección del
inconsciente colectivo...Por
lo tanto, podemos estudiar el
inconsciente colectivo de dos
maneras: en la mitología o en
el análisis del individuo (Jung,
2007, p. 323).

Imágenes primordiales son cruciales en este caso de "Hinge-Chair"; de la Gran Madre (diosa) es un caso en particular; como puede ser personajes como Isis, Atenea, Venus, Vesta y Columbia. Otro concepto relacionado es el del ánima que es el aspecto femenino interno del hombre. "El ánima es el arquetipo de la 
vida misma (Jung, 2015b, p.27).” El ánima es tanto un complejo personal como una imagen arquetípica de mujer en la psique masculina. Es un factor inconsciente encarnado en cada niño, y es responsable del mecanismo de proyección. Inicialmente identificada con la madre personal, el ánima se vivencia más adelante no sólo en otras mujeres, sino como una penetrante influencia en la vida de un hombre.

[En el hombre] existe un imago no sólo de la madre sino de la hija, la hermana, la amada, la diosa celestial y la diosa infernal. Cada madre y cada amada está obligada a convertirse en portadora y encarnación de esta imagen omnipresente y eterna, que corresponde a la realidad más profunda de un hombre (Jung, 2015a, p.78).

Jung distinguió cuatro etapas esenciales del ánima, análogas a los niveles del culto de Eros descritos en el último periodo clásico. Las personificó como Eva, Helena, María y Sofía. En la primera etapa, Eva, el ánima es indistinguible de la madre personal. El hombre no puede funcionar bien sin una relación estrecha con una mujer. En la segunda etapa, personificada en la figura histórica de Helena de Troya, el ánima es una imagen sexual colectiva e ideal. La tercera etapa, María, se manifiesta en sentimientos religiosos y en la capacidad de mantener relaciones duraderas. En la cuarta etapa, como Sofía, el ánima del hombre funciona como guía de la vida interior, llevada a la conciencia los contenidos del inconsciente. Coopera en la búsqueda de significado y es la musa creativa en la vida de un artista. No importa dónde se encuentra un hombre en términos de desarrollo psicológico, siempre será propenso a ver los aspectos de su ánima, su alma, en una mujer real (Jung, 1964).

El arquetipo femenino es poderoso en este contexto; el arquetipo está constituido por elementos estructurales y primordiales de la psique humana. Los arquetipos no pueden ser representados como tales, pero sus efectos son discernibles en imágenes y motivos arquetípicos.

\section{Raimund Abraham constructs an Urwelt, a domain of alienated originality within the familiar and conventionalized, in which it is possible to invent the archetype itself for the first time, as though it were the very essence of the new (Groihofer, Woods, 2011, 1993, p.225).}

Carl Jung en su vida profesional llegó a observar y a estudiar un numeroso grupo de pacientes (80,000 sueños) y descubrió que estos estudios proyectaron un patrón. A este patrón Jung designó el término "el proceso de individuación" que es en esencia un proceso de crecimiento psíquico de maduración del individuo. Según Jung, nadie está nunca completamente como individuo. Mientras la meta sea la totalidad y una sana relación de trabajo con el sí mismo (self), el verdadero valor de la individuación reside en lo que va ocurriendo en el camino. "La meta es importante sólo como una idea; lo esencial es el opus que conduce a la meta: ése es el objetivo de toda una vida (Jung, 2015a, p. 335)".

Es aún más vital el papel que desempeña el ánima en ayudar a que la mente del hombre esté en sintonía con los valores internos correctos y por ende abrirse hacia las profundidades internas todavía más profundas. El ánima asume el rol de guía, o mediadora, hacia la vida interna del sí mismo; esto es el papel de Beatrice en el Paradiso de Dante, para poder iniciarle hacia una forma de vida más alta y espiritual.

I think one cannot walk away tonight without making a clear statement about the necessity for our spiritual survival, to protect the autonomy of art 
against any society, totalitarian or democratic. Before anybody becomes a citizen, he has to be an individual. It ultimately deals with our individual survival, (Franck, Abraham, p.63).

Otros aspectos de la obra de Abraham son las connotaciones de los variados arquetipos que se podrán manifestar debido a su consecuencia. Un ejemplo es el de la diosa Venus en la tradición artística y la historia del arte que han demostrado a Venus en dos formas esenciales; la Venus Genetrix ('madre'), en su papel como ancestro del pueblo romano, una diosa de la maternidad y la vida doméstica. Como Venus era considerada en concreto la madre del gens juliano, Julio César le dedicó un templo en Roma. Este nombre también se aplica a un tipo iconológico de estatua de Afrodita/Venus (Clark, 1990).

La segunda forma es la de la Venus Ericina ('del brezo), por el monte Erice (oeste de Sicilia), uno de los centros de su culto. Se le dedicaron templos en la colina Capitolina de Roma y fuera de la Porta Collina. Personifica el amor "impuro" y era la diosa patrona de las prostitutas (Lloyd-Morgan, 1986).

Esta dualidad mitológica se puede apreciar en los registros fotográficos de la obra de Abraham que demuestran las diferentes posiciones de la modelo femenina y es enfatizado por el hecho de que hay dos versiones uno en "positivo" y otro en "negativo" fotográfico, que, además, se puede interpretar como la diosa/ mujer púdica o impúdica.

\section{Conclusión}

Early in their careers, Abraham and Pichler were closely associated with each other... What they share in common perhaps-aside from the obsession with the latent anima in form - is this preoccupation with the cataclysmic moment in which a massive stone block splits apart or, inexplicably, a crevice opens up in the earth's surface as a prelude to the outpouring of some subterranean source (Lepik, Frampton, 2010, p.108).

En efecto el acto de la catástrofe se puede entender como un símbolo para el acto sacrificial. La apreciación que hace Kenneth Frampton es bastante atinada en este efecto. Frampton fue un amigo muy cercano de Abraham y quizás por esta razón invoca el papel del ánima que por cierto es importante en el proceso de individuación del inconsciente que a su vez es expresado por la ruptura del bloque telúrico, tectónicamente manifestado. La grieta que se presenta como resultado de la ruptura indica una fuerza, una fuente subterránea que es análogo al subconsciente. Lo sagrado se nota cuando el hombre entra en conocimiento de lo sagrado, porque se manifiesta como algo disparejo por completo de lo profano. Para denominar el acto de esa manifestación de lo sagrado podría decirse que la historia de las religiones, de las más primitivas a las más elaboradas, está constituida por un acopio de manifestaciones de las realidades sacras. Se trata siempre del mismo acto misterioso: la expresión de algo completamente diferente, de una realidad que no pertenece a nuestro mundo, en objetos que forman parte integrante de nuestro mundo natural, o profano (Jung, 2015b).

En la cultura mediterránea, el progreso de la obra artística/arquitectónica sagrada ha estado transmitido de un significado simbólico, que envuelve la existencia de creencias muy concretas acerca de la relación entre el hombre y el orden universal. La apreciación y la pasión que Abraham sostenía por la geometría es también 
un factor clave para entender su obra. La geometría viene a jugar un papel importante; es un camino para comprender quienes somos, de dónde venimos y adónde vamos; es una ciencia antigua heredada por el antiguo conocimiento hermético egipcio y griego como símbolo del asenso espiritual y conexión entre el cielo y la tierra. Residimos en un Universo semiótico, es decir, cimentados a partir de procesos de significación. Fabricamos estos significados en base a signos, ordenaciones, lenguajes y símbolos.

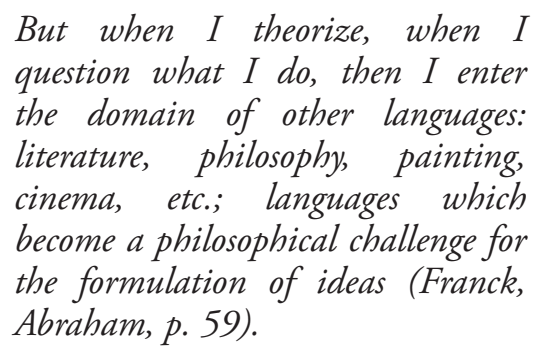

En la antigüedad existió una creencia muy extendida acerca de la existencia de varios cielos o esferas celestes superpuestas, que estarían en consonancia con las diferentes jerarquías de espíritus existentes, así como con las diversas etapas por las que habría de pasar el alma en su proceso de purificación. Pues bien, tradicionalmente se ha atribuido al círculo el simbolismo de los espacios celestes. El círculo, símbolo de la unidad de lo absoluto en la medida en que se une a sí mismo, encerraría la suprema perfección, oponiéndose a lo terrenal que es representado por el cuadrado, símbolo de todo lo estático y puramente material. No obstante, las funciones del ánima como guía interior son positivas cuando el hombre las toma seriamente. Los sentimientos, estados de ánimo, expectativas y fantasías que le envía el ánima y cuando las fija a una forma. Por ejemplo- en la escritura, pintura, escultura, composición musical o la danza. Cuando una obra es lentamente trabajada con paciencia, otros materiales inconscientes más profundos se manifestarán y se unirán con el material inicial menos desarrollado. Después que una fantasía o creación ha sido fijada en alguna forma específica, debe ser examinada tanto intelectual como éticamente, con un sentido de evaluación resultante.

...So that unless we have the
freedom to express ourselves
through the means of our
imagination, we are all dead
(Franck, Abraham, p. 63).

Los movimientos estéticos que se articulan cada vez con mayor fuerza en diferentes lugares espirituales de hoy en día se alimentan de las vanguardias de principios del siglo XX. Es propia de esos movimientos la tendencia a llevar tan al extremo la autonomía del arte, aquello que la presencia o presentación estética había de llevar consigo como mensaje de contenido interpretable. Tras el final de la vanguardia histórica, la vanguardia puede recurrir a su prehistoria y sacar provecho de lo que siempre dominó como un arte: la percepción, la observación. La penetración de la actividad productiva en los pensamientos, sentimientos y representaciones propios. El motivo estriba en que el presente siempre hay que pensarlo como una constelación de algo que está lejano y cercano, como una constelación de presencia y ausencia.

\section{Bibliografía:}

Craft, C. (2012). An Audience of Artists: Dada, Neo-Dada, and the Emergence of Abstract Expressionism. Chicago: University of Chicago.

Clark, K. (1990). The Nude, A study in ideal form. Princeton: Princeton University Press.

Derrida, J. (1994). Márgenes de la Filosofía. Madrid: Ediciones Cátedra, S. A.

Franck, P., Franck, B. (1985). "Architecture and Abstraction", Pratt Journal of Architecture, Vol. 1. New York: Rizzoli International Publication, Inc. 
Groihofer, B. (2011). Raimund Abraham, [UN] BUILT $2^{\text {nd }}$ Ed., Vienna: Springer-Verlag.

Jung, C. G. (2007). "Dos escritos sobre psicología Analítica", Obras completas, Vol. 7. Madrid: Editorial Trotta, S. A.

Jung, C. G. (2011). "La Dinámica de lo Inconsciente", Obra completa, Vol.8. Madrid: Editorial Trotta, S. A.

Jung, C. G. (2015a). "Los Arquetipos y lo Inconsciente colectivo", Obras completas, Vol. 9/1. Madrid: Editorial Trotta, S. A.

Jung, C. G. (2015b). "Estudios sobre Representaciones Alquímicas", Obras completas, Vol. 13. Madrid: Editorial Trotta, S. A.

Jung, C. G. (1964). Man and his symbols. New York: Doubleday \& Company.

Kamuf, P. (1991). A Derrida reader: between the blinds. New York: Columbia University Press.

Lloyd-Morgan, G. (1986). "Roman Venus: public worship and private rites". Pagan Gods and Shrines of the Roman Empire. Oxford: Oxford Committee for Archaeology Monograph 8.

Lepik, A., Stadler, A. (2010). Raimund Abraham and the Austrian Cultural Forum New York. Ostfildern: Hatje Cantz Verlag.

Noever, P., Prix, W. (2010). In the Absence of Raimund Abraham. Ostfildern: Hatje Cantz Verlag.

Norberg-Schulz, Chr. (1999). Arquitectura Occidental. Barcelona: Editorial Gustavo Gili.

http://definicion.de/bisagra/\#ixzz4IaQQEJvt). RevisadoAgosto 27, 2016.

https://es.wikipedia.org/wiki/Tímpano_(arquitectura) Revisado - Agosto 29, 2016.

http://definicion.de/articulacion/\#ixzz4IgP25baK.

Revisado- 27, 2016. 